\title{
Correction to: Management, Uncertainty, and Accounting
}

Correction to:

(C) The Author(s) 2019

A. Nishimura, Management, Uncertainty, and Accounting, https://doi.org/10.1007/978-981-10-8989-3

The original version of the book contained an error that has been corrected.

The city in the affiliation has been changed as below

"Oita-city" in the following phrase (Akira Nishimura, Beppu University, Oita-city, Oita) has been changed to "Beppu-city".

The updated original online version for this chapter can be found https://doi.org/10.1007/978-981-10-8989-3

(C) The Author(s) 2019

A. Nishimura, Management, Uncertainty, and Accounting, https://doi.org/10.1007/978-981-10-8989-3_13 